\title{
PENERAPAN METODE FUZZY PADA ROBOT PENYEDOT DEBU
}

\author{
Andi Yulio Pratama, Karina Auliasari, Mira Orisa \\ Program Studi Teknik Informatika S1, Fakultas Teknologi Industri \\ Institut Teknologi Nasional Malang, Jalan Raya Karanglo km 2 Malang, Indonesia \\ andiyupratama69@gmail.com
}

\begin{abstract}
ABSTRAK
Mayoritas masyarakat pada umumnya membersihkan rumah menggunakan alat sapu dan vacuum cleaner secara manual dalam membersihkan debu atau sampah pada ruangan. Saat ini sudah banyak robot vacuum cleaner yang dijual bebas, namun sebagian besar harga robot vacuum cleaner relatif mahal dan tidak menggunakan algoritma dalam navigasinya. Dari permasalahan tersebut peneliti ingin membuat sebuah mobil robot vacuum cleaner yang dapat dikontrol oleh manusia. Penelitian ini merupakan rancangan mobil robot vacuum cleaner yang berguna untuk meringankan pekerjaan manusia dengan menggunakan Arduino Uno sebagai otak robot vacuum cleaner dan dapat dikontrol oleh manusia dengan ponsel berbasis Android. Kebutuhan pada alat yang dikembangkan ini mencakup dari Arduino Uno sebagai otak pemroses gerak mobil, sensor ultrasonik untuk mendeteksi jalur mana yang bebas halangan, motor dc sebagai penggerak mobil robot, dan bluetooth sebagai penghubung aplikasi Android dengan mobil robot vacuum cleaner. Dari hasil penelitian yang telah dilakukan, alat mobil robot vacuum cleaner dapat membersihkan area ruangan dan pergerakan mobil robot secara otomatis bergerak menggunakan metode fuzzy untuk mendeteksi jalur yang bebas halangan. Mobil robot bisa diberhentikan dengan aplikasi Android apabila kegiatan pembesrihan rumah sudah selesai
\end{abstract}

Kata Kunci : robot, vacuum cleaner, sensor ultrasonik, metode fuzzy

\section{PENDAHULUAN}

Lingkungan merupakan tempat manusia hidup dan berkumpul. Lingkungan juga menjadi salah satu faktor yang dapat mempengaruhi kehidupan manusia, termasuk segala aktivitas kehidupan manusia, mulai dari gaya hidup, cara berprilaku, pola pikir, bahkan kepribadian. Oleh karena itu, sudah sepatutnya jika kita menjadikan lingkungan tempat tinggal menjadi senyaman mungkin dengan cara menjaga kebersihan lingkungan tempat tinggal. Proses membersihkan rumah dapat menjadi suatu pekerjaan yang cukup berat meskipun terlihat mudah dilakukan. Kegiatan membersihkan rumah membutukan kedisplinan agar membuat rumah menjadi bersih, tidak berantakan, dan enak dipandang.

Mayoritas masyarakat pada umumnya menggunakan sapu dan vacuum cleaner yang masih membutuhkan tenaga manusia dan sangat menguras waktu untuk mengoperasikannya. Sudah ada robot vacuum cleaner yang dijual bebas untuk membantu membersihkan debu atau sampah pada ruangan, namun sebagian besar harga robot vacuum cleaner relatif mahal dan tidak menggunakan algoritma dalam navigasinya.

Dari uraian permasalahan ini, penulis ingin membuat penelitian dengan tujuan untuk merancang sebuah mobil robot vacuum cleaner yang dapat membersihkan lantai ruangan secara bersih yang berguna untuk meringankan pekerjaan manusia dengan menggunakan Arduino Uno sebagai otak robot vacuum cleaner dan dapat dikontrol oleh manusia dengan handphone berbasis Android. Mobil robot vacuum cleaner ini. Dari mobil robot vacuum cleaner ini, pemasalahan untuk membersihkan debu rumah bisa teratasi dengan menyalakan mobil robot vacuum cleaner dan mobil robot akan bergerak secara otomatis.untuk bergerak. Pergerakan otomatis menggunakan metode fuzzy sebagai algoritma perangkat agar mobil robot bisa menentukan jalur mana yang bebas halangan dan mobil robot bisa diberhentikan apabila kegiatan pembersihan rumah sudah selesai.

\section{TINJAUAN PUSTAKA \\ 2.1 Penelitian Terdahulu}

Dari penelitian Sumarsono (2018) berjudul "Pengembagan Mikrokontroller Sebagai Remote kontrol Berbasis Android" tersebut Sumarsono menggunakan mikrokontroller ATMega16 dan motor servo. Motor servo ini diintegrasikan dengan mikrokontroller dalam menggerakkan pintu gerbang rumah dan juga diintegrasikan dengan ponsel Android. Dan hasil penelitian yang dilakukan mendapatkan kesimpulan bahwa prototipe ini berhasil dirancang dan antar alat dapat berkomunikasi dengan baik sehingga pergerakan pintu gerbang rumah sepenuhnya mampu dikontrol oleh smartphone Android (Sumarsono, 2018).

Nanda (2016) dalam penelitiannya membuat "Sistem Pengendalian Remote Control Mini-Blimp Menggunakan Android Smartphone Dengan Komunikasi Bluetooth". Dari hasil penelitiannya penggunaan aplikasi pada android menggunakan koneksi bluetooth dapat mengendalikan gerak miniblimp, dari pengendalian tersebut motor dc dan motor servo yang digunakan bekerja sesuai user, tingkat keberhasilan pergerakan saat terbang mengudara sebesar $60 \%$ dan laju mini-blimp saat terbang dalam 
ruangan tertutup belum sempurna dikarenakan balon tidak dapat mengangkat beban komponen eletronis dengan sempurna (Nanda H, 2016).

Setiawan (2016) dengan judul "Rancang Bangun Robot Mobil Control Sederhana Menggunakan Arduino Berbasis Android Sistem" membuat mainan mobil remot ini digemari oleh anak-anak. Dengan menggunakan bluetooth dan Arduino Setiawan dapat merancang dan membangun mobil remot kontrol berbasiskan Android, dan diharapkan mobil remot control ini dapat membuat anak-anak bisa mengenali dan merangkai sebagai latiha meningkatkan kreativitas anak (Setiawan D,2016).

Suwanda (2014) pada jurnalnya yang berjudul "Rancang Bangun Robot Omni Wheel Penyedot Debu Menggunakan Sensor Accelerometer Berbasis Mikrokontroller ATMega16" dengan hasil uji yakni mobile robot yang menggunakan omni wheel dapat bergerak ke segala arah pada bidang yang datardan bergerak secara efisien. (Suwanda I, 2014).

Ihsan (2020) pada penelitiannya yang berjudul "Sistem Penentu Karyawan Terbaik Dengan Metode Fuzzy Mamdani Menggunakan Radio Frequency Identification (RFID) Sebagai Presensi" dari penelitiannya aplikasi yang dikembangkan dapat mempermudah para karyawan dalam melakukan presensi kehadiran, dengan adanya sistem ini perusahaan dapat memantau kehadiran absensi para karyawan secara efisien dan terkomputerisasi (Ihsan A.M,2020).

\subsection{Fuzzy}

Fuzzy adalah sebuah metode untuk memetakan suatu ruang input ke dalam ruang output. Penggunaan logika fuzzy dalam sistem tradisional dirancang untuk mengontrol keluaran tunggal yang berasal dari beberapa masukan yang tidak saling berhubungan. Sistem fuzzy mempunyai beberapa keuntungan bila dibandingkan dengan sistem tradisional, misalkan pada jumlah aturan yang dipergunakan. Pemrosesan awal sejumlah besar nilai menjadi sebuah nilai derajat kanggotaan pada sistem fuzzy mengurangi jumlah nilai menjadi sebuah nilai derajat keanggotaan pada sistem fuzzy, dari derajat keanggotaan itulah dapat mengurangi jumlah nilai yang harus dipergunakan pengontrol untuk membuat suatu keputusan (Marimin, 2005).

\subsection{Langkah-langkah Perhitungan Fuzzy}

a. Buat logika fuzzy, logika fuzzy didapat dari setelah menentukan dua variabel dari satu Input dan satu Output, keduanya akan kit acari lebih terdahuli nilai keanggotaanya. Nilai keanggotaan diambil dari menggunakan Parameter jarak diambil dari bacaan sensor ultrasonik (Input) dan Motor DC(Output), parameter jarak ini memiliki variabel linguistik jauh () dan dekat $(<30 \mathrm{~cm})$. sedangkan untuk variabel dari parameter Motor DC yaitu maju (lurus) dan maju ,belok kanan/kiri. b. Tetapkan aturan/ rule untuk nilai keanggotaan, pertama (1) diketahui parameter dari input sensor jarak : jauh dan dekat, kedua (2) diketahui parameter dari output motor dc maju (lurus) dan maju ,belok kanan/kiri. Rule fuzzy yang ditetapkan yaitu:

- Jika jarak dekat maka maju, belok kanan/kiri.

- Jika jarak jauh maka maju (lurus).

c. Buat nilai keanggotaan dengan nilai yang diambil dari variabel input dan variabel output. Grafik nilai keanggotaan input dan output pada gambar 1 grafik nilai keanggotaan.
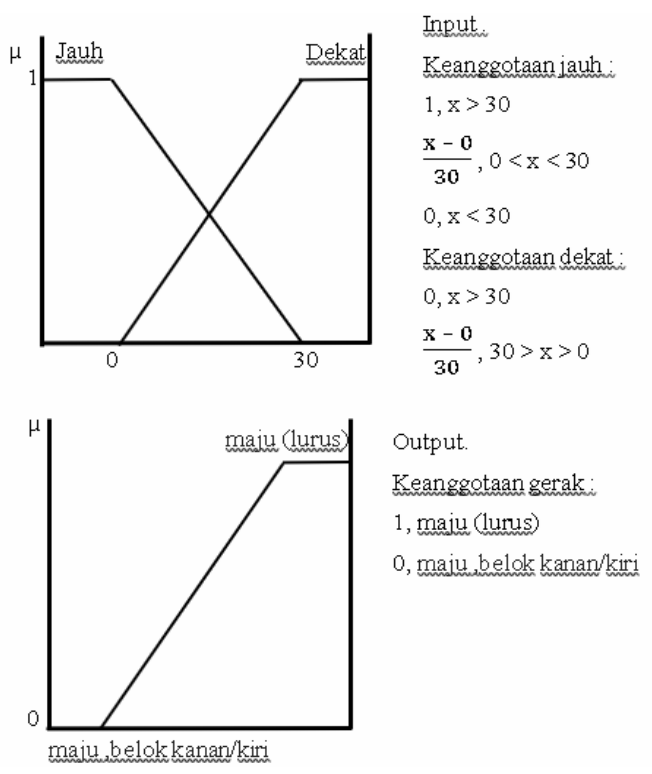

Gambar 1 grafik nilai keanggotaan

d. Menentukan rumus pada rule, rule 1 : a. Jika jarak dekat maka maju, belok kanan/kiri dan rule 2 : Jika jarak jauh maka maju (lurus), sebagai berikut:

Rule $1=0+(x * 30)$

Rule $2=(x * 30)+0$;

e. Melakukan tahap fuzzifikasi, rumus fuzzifikasi yakni hasil $=\frac{(\text { rule1 } * x)+(\text { rule } 2 * x)}{(x+x)}$

f. Melakukan defuzzifikasi dengan metode Center Of Sum (COS), dengan rumus $\sum$ $\frac{(\text { rule } 1 * \text { jarak } 1)+(\text { rule } 2 * \text { jarak } 2)}{(\text { jarak } 1+\text { jarak } 2)}$, dari nilai yang didapat rumus tersebut akan diambil nilainya dan dibandingkan dengan nilai rule1 dan rule2 apakah hasil memenuhi salah satu rule. Jika salah satu rule terpenuhi maka mobil robot akan mendapat perintah dari rule. 


\subsection{Android}

Android adalah sebuah sistem operasi yang dirancang oleh perusahaan Google dengan basis kernel Linux dan jugaberbagai perangkat lunak seperti open source dan lainnya. Ponsel yang menggunakan Android dapat digunakan untuk perangkat dengan layer sentuh seperti pada smartphone dan juga computer tablet. Android memiliki perbedaan dengansistem operasi windows 10 milik Microsoft yang mengharuskan perusahaan membayar royalti apabila ingin menggunakan sistem operasi tersebut. Sedangkan untuk sistem operasi seperti iOS milik perusahaan Apple hanya dapat digunakan pada perangkat iphone dan juga ipad. Pada dasarnya, Google sendiri mendapatkank keuntungan apabila ada perusahaan atau pengembang apliaksi mereka sendir ke googleplay store. Tidak hanya itu, keuntungan tersebut juga bisa didapatkan dari iklan yang muncul ketika anda sedang menggunakan aplikasi atau game tertentu.

Android merupakan sistem operasi yang banyak digunakan karena ia dapat dengan mudah ditemukan dan fleksibel untuk dioperasikan. Tidak seperti sistem operasi IOS yang dirilis perusahaan Apple yang khusus untuk produk iphone dan juga ipad. Apple tidak merilis sistem IOS untuk perangkat lain diluar perangkat mereka sendiri. (Salamadian, 2019)

\subsection{Modul Bluetooth HC-05}

Modul bluetooth HC-05 adalah modul komunikasi nirkabel via bluetooth yang beroperasi pada ferkuensi $2.4 \mathrm{Ghz}$ dengan pilihan dua mode konektivitas .

1. Mode 1 berperan sebagai slsve atau receiver data saja,

2. Mode 2 berperan sebagai master atau dapat bertindak sebagai transceiver.

Pengaplikasian kompoenen ini sangat cocok pada proyek elektronika denga komunikasi nirkabel. Aplikasi yang dimaksud antara lain aplikasi sistem kendali, monitoring, maupun gabugan keduanya antarmuka yang dipergunakan untuk mengakses modul ini yaitu serial TXD, RXD, VCC serta GND. Serta terdapat LED (built in) sebagai indikator koneksi bluetooth terhadap perangkat lainnya seperti sesame modul, dengan smartphone, dan sebagainya (Ilmu nyebar, 2017).

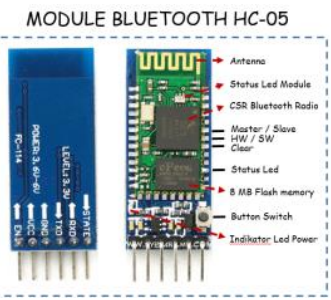

Gambar 2. Module Bluetooth HC-05
Jangkauan jarak efektif saat modul in terkoneksi dalam range 10 meter, dan jika melebihi dari range tersebut maka kualitas konektivitas akan semakin kurang maksimal (Ilmu nyebar, 2017).

Spesifikasi dari modul bluetooth ini :

a. Frekuensi kerja $2.4 \mathrm{GHz}$

b. Bluetooth protocol tipe v2.0+EDR

c. Kecepatan data dapat mencapai 1 Mbps pada mode sinkron

d. Kecepatan dapat mencapai $2.1 \mathrm{Mbps} / 160 \mathrm{kbps}$ pada mode asinkron maksium

e. Teggangan kerja pada rentang 3,3-6 Volt DC

f. Konsumsi arus kerja yaitu $50 \mathrm{~mA}$

g. Memiliki modulasi Gaussian Frequency Shift Keying (GFSK)

h. Sensitivitas $-84 \mathrm{dBm}(0.1 \%$ BER $)$

i. Daya emisi $4 \mathrm{dBm}$

j. Suhu operasional range $-20^{\circ} \mathrm{C}-+75^{\circ} \mathrm{C}$

\subsection{Modul Driver Motor L298n}

Merupakan modul motor driver motor DC yang paling banyak digunakan didunia elektronika yang difungsikan untuk mengontrol kecepatan serat arah perputaran motor DC.

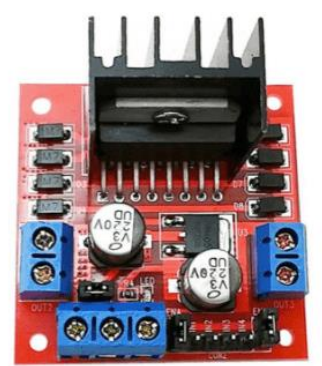

Gambar 3. Modul Driver Motor L298N

IC L298 mrupakan sebuah IC tipe H-bridge yang mampu mengendalikan beban-beban induktif seperti relay, solenoid, motor DC dan motor stepper. Pada ICL298n terdiri dari transistor-transistor logic (TTL) dengan gerband nand yang berfungsi untuk memudahkan dalam menetukan arah putaran suatu motor DC maupun motor stepper (Ilmu nyebar, 2017). Spesifikasi modul motor Driver Motor L298N:

a. Menggunakan IC L298N (Double H bridge Drive Chip)

b. Tegangan minimal untuk masukan power antara $5 \mathrm{~V}-35 \mathrm{~V}$

c. Tegangan operasional : $5 \mathrm{~V}$

d. Arus untuk masukan antara $0-36 \mathrm{~mA}$

e. Arus maksimal untuk keluaran per output A maupun $\mathrm{B}$ yaitu $2 \mathrm{~A}$

f. Daya maksimal yaitu $25 \mathrm{~W}$

g. Dimensi modul yaitu $43 \times 43 \times 26 \mathrm{~mm}$

h. Berat : $26 \mathrm{~g}$ 


\subsection{Motor DC}

Motor DC merupakan aktuator yang paling banyak digunakan dalam aplikasi robotik. Motor DC buatan Korea yang satu ini dikemas dalam kotak plastik yang kokoh, dilengkapi dengan geartrain yang mampu memberikan torque yang cukup besar (Ilmu nyebar, 2017).

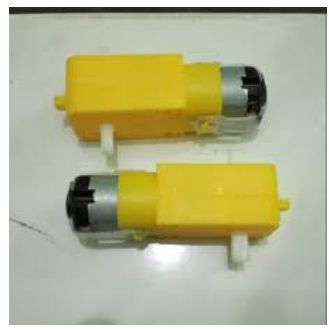

Gambar 4. motor DC

Spesifikasi motor DC :

a. Tegangan $: 3 \mathrm{v}-6 \mathrm{v}$

b. Rpm : 100-200

c. Dimensi motor : 2.76 in x 1.46 in $x 0.87$ in $(7 \mathrm{~cm}$ x $3.7 \mathrm{~cm} \times 2.2 \mathrm{~cm})$.

\subsection{Modul Sensor Ultrasonik (HC-SR04)}

Sensor jenis ini adalah sebuah sensor jarak dengan modul sensor ultrasonik untuk mendeteksi sebuah objek menggunakan pantulan suara. Sensor ultrasonik terdiri dari transmitter (Pemancar) dan sebuah receiver (penerima). Transmitter berfungsi untuk memancarkan sebuah gelombang suara kearah depan. Jika sebuah objek depan transmitter maka sinyal tersebut akan memantul kemabali ke receiver. Fungsi sensor ultrasonik adalah mendeteksi benda atau objek dihadapan sensor. Penerapannya banyak dipakai pada robot pemadam api dan robot obstacle lainnya. Salah satu sensor yang paling sering digunakan adalah sensor ultrasonik tipe HC-SR04. Sensor ini dapat digunakan untuk mengukur jarak antara penghalang dan sensor. Sensor ini mirip dengan sensor PING (Ilmu nyebar, 2017).

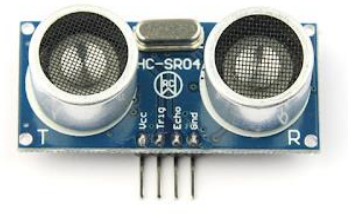

Gambar 5. Sensor Ultrasonik HC-Sr04

Spesikasi sensor ultrasonik :
a. Tegangan : 5V DC
b. Arus statis : $<2 \mathrm{~mA}$
c. Level output : $5 \mathrm{v}-0 \mathrm{~V}$
d. Sudut sensor : $<15$ derajat
e. Jarak yg bisa dideteksi : $2 \mathrm{~cm}-450 \mathrm{~cm}(4.5 \mathrm{~m})$
f. Tingkat keakuratan : up to $0.3 \mathrm{~cm}(3 \mathrm{~mm})$

\subsection{Vacuum Cleaner}

Vacuum cleaner adalah mesin penghisap debu yang menggunakan pompa udara untuk menciptakan keadaan kosong, unutk menghisap debu dan kotoranyang biasanya berasal dari lantai. Sebagian besar rumah dengan lantai berkapet menggunakan vacuum cleaner sebagai alat pembersihnya. Kotoran dikumpulkan dengan sistem penyaringan maupun silicon untuk kemudian dibuang. Vacuum cleaner secara umum digunakan untuk menghisap debuatau kotoran. Hanya saja daya hisap yang dimiliki tidak tinggi hanya bisa menyedot debu/pasir halus, dan barang kecil yang ringan (Ikame,2017).

Spesifikasi vacuum cleaner yang digunakan :
a. Bahan: plastik dan karbon
b. Kecepatan terukur : $3200 \mathrm{r} /$ menit
c. Tegangan terperingkat: $220 \mathrm{~V}$
d. Daya Terperingkat: $50 \mathrm{~W}$
e. Ukuran: $29 \times 11 \times 6 \mathrm{~cm}$

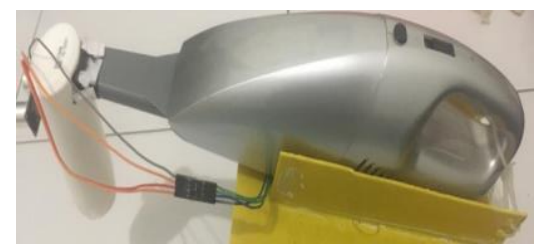

Gambar 6. vacuum cleaner

\section{METODE PENELITIAN}

\subsection{Blok Diagram Sistem}

Blok diagram sistem adalah diagram dari sebuah sistem, ponsel android akan melakukan koneksi dengan mobil robot vacuum cleaner dengan koneksi bluetooth .Proses koneksi Bluetooth akan dijalankan oleh modul bluetooth HC-05 dari kontrol Arduino. Setelah mobil robot vacuum cleaner telah terhubung maka mobil robot vacuum cleaner bergerak digerakkan dengan motor driver 129n dari kontrol Arduino.

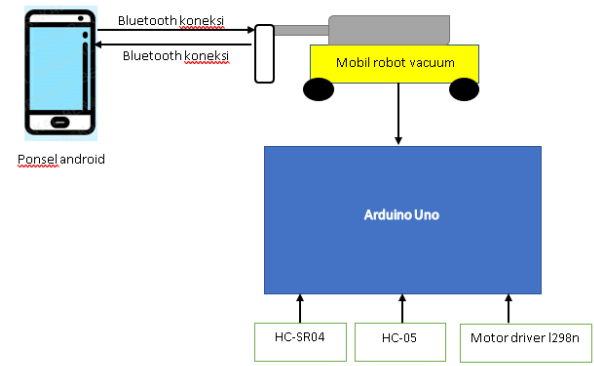

Gambar 7. Blok diagram sistem

\subsection{Flowchart sistem mobil robot vacuum cleaner}

Flowchart sistem ini menjelaskan proses berjalannya sistem menggunakan mobil robot vacuum cleaner seperti ditunjukkan pada Gambar 8 


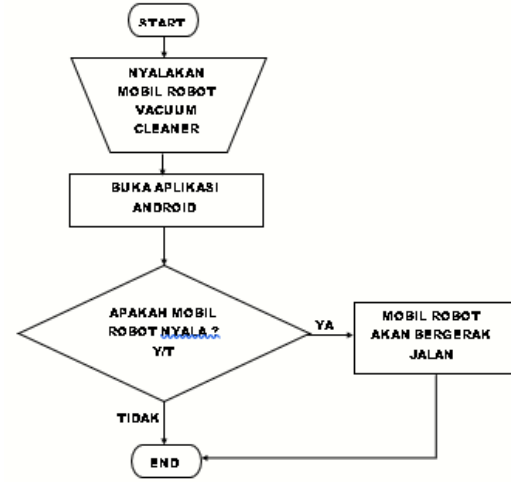

Gambar 8. Flowchart Sistem

Penjelasan gambar : nyalakan mobil robot vacuum cleaner dan buka aplikasi android mobil robot vacuum cleaner, apakah mobil robot vacuum cleaner sudah nyala ? jika ya maka mobil robot vacuum cleaner bergerak jalan, jika tidak mobil robot vacuum cleaner tidak jalan.

\subsection{Flowchart sistem aplikasi mobil rc}

Flowchart sistem ini menjelaskan proses berjalannya aplikasi seperti ditunjukkan pada Gambar 9

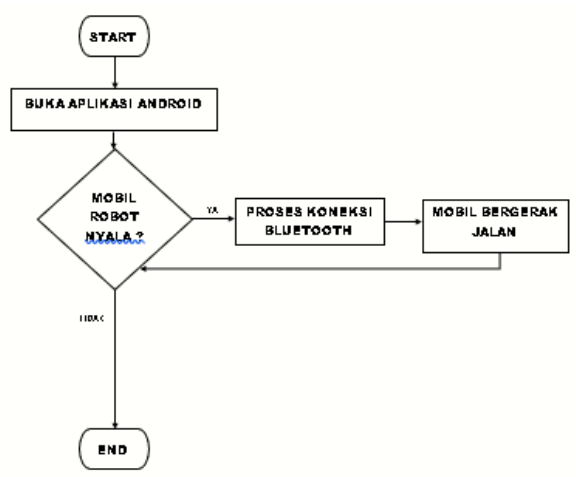

Gambar 9. Flowchart aplikasi

Penjelasan gambar : mula-mula buka aplikasi android mobil robot vacuum cleaner, mobil robot vacuum cleaner sudah nyala? Jika ya , proses koneksi Bluetooth ponsel ke modul bluetooh HC-05. Ingin mobil robot off? Jika ya mobil robot akan berhenti dan selesai.

\subsection{Desain Wiring mobil robot vacuum cleaner}

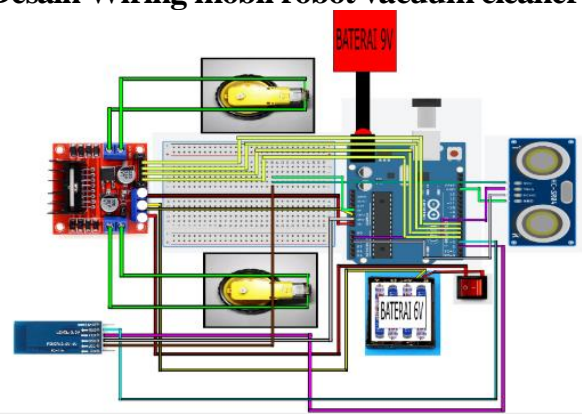

Gambar 10. desain wiring mobil robot vacuum cleaner

\section{HASIL DAN PEMBAHASAN}

4.1. Hasil Implementasi

1. Menyalakan power switch mobil robot dan vacuum cleaner seperti pada gambar 11 menyalakan power switch mobil robot \& vacuum cleaner.

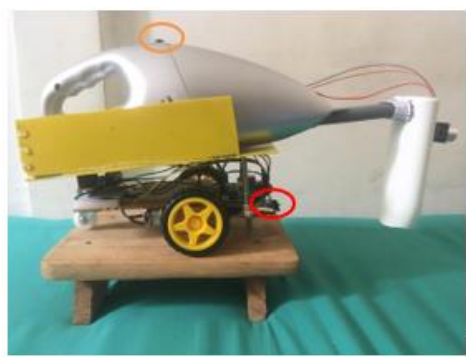

Gambar 11. menyalakan power switch mobil robot vacuum cleaner

Pejelasan gambar : gambar 4.1 terdapat lingkaran oranye yang menunjukkan power switch untuk menyalakan power mobil robot dan lingkar merah yang menunjukkan power switch untuk menyalakan power vacuum cleaner.

2. Koneksikan Bluetooth ponsel android dengan mobil robot, Bluetooth pada mobil robot bernama "HC-05" seperti gambar 12 koneksi Bluetooth ponsel android dengan mobil robot.

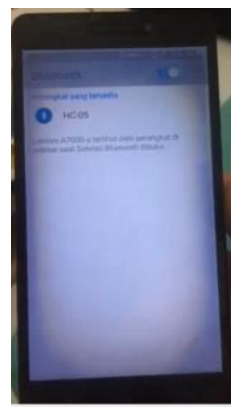

Gambar 12. koneksi Bluetooth ponsel android dengan mobil robot.

Penjelasan gambar : gambar 12 menunjukkan koneksi bluetooth ponsel android dengan mobil robot bernama HC-05.

3. Buka aplikasi mobil re seperti pada gambar 13 aplikasi mobil robot vacuum cleaner

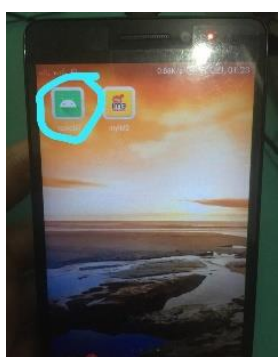

Gambar 13. aplikasi mobil rc 
4. Klik tombol cari dan hubungkan, tombol cari digunakan untuk mencari perangkat bluetooth yang telah terkoneksi dan tombol hubungkan digunakan untuk proses koneksi seperti gambar 14 tombol cari dan hubungkan

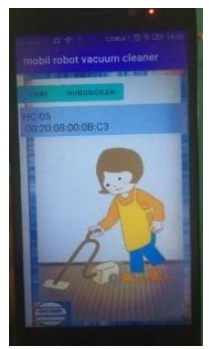

Gambar 14. tombol cari dan hubungkan

5. Jika sudah klik tombol hubungkan, akan masuk ke menu tombol on dan off, seperti gambar 15 tombol on dan off.

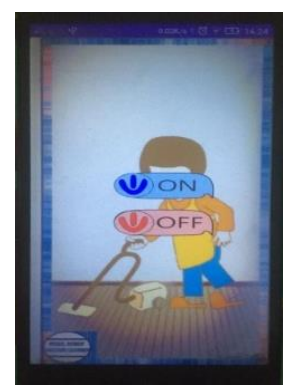

Gambar 15. tombol on dan off.

Penjelasan gambar : pada gambar 15 menunjukkan menu program dengan tombol on dan off. Tombol on digunakan untuk membuat mobil bergerak secara otomatis dan tombol off digunakan untuk membuat mobil robot berhenti.

6. Jalan gerak mobil, sebelum membuka aplikasi mobil sebenarnya sudah nyala dengan kondisi mobil bergerak secara otomatis, di dalam aplikasi hanya untuk membuat tombol seperti remote untuk membuat berhenti mobil (tombol off) dan membuat mobil bergerak otomatis (tombol on). Gambar 16 gerak mobil berhenti saat ada halangan

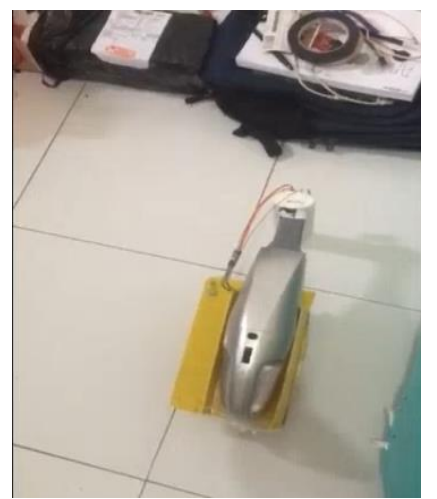

Gambar 16. gerak mobil berhenti saat ada halangan
7. Saat mobil robot ingin tidak dipakai, buka aplikasi mobil rc kembalik lalu klik tombol off agar mobil berhenti.

8. Matikan power switch mobil robot dan vacuum cleaner saat mobil robot vacuum cleaner sudah tidak dipakai.

\subsection{Skenario pengujian}

Skenario pengujian adalah bentuk pengujian pada alat mobil robot vacuum cleaner baik dari pemgujian dalam aplikasi dan pengujian gerak mobil robot vacuum cleaner. Dalam pengujian baterai yang digunakan untuk menggerakkan mobil robot vacuum cleaner yang digunakan sebesar $15 \mathrm{~V}$. Dalam uji ketahanan baterai untuk mobil robot vacuum cleaner, mobil bergerak atau digunakan kurang lebih 15 menit jam dalam kurun waktu sampai 5 hari, batas baterai mobil hanya bisa bertahan dalam pengunaan 15 menit (5 kali) berarti maksimal 1 jam 15 menit. Untuk pemasangan aplikasi android dilakukan dengan standalone (memasang dengan sendiri) dalam bentuk file .apk dan langsung dipasang di ponsel.

Tabel 1. skenario pengujian penggunaan aplikasi android mobil robot vacuum cleaner.

\begin{tabular}{|l|l|l|l|}
\hline No & \multicolumn{2}{|c|}{ Skenario uji } & \multicolumn{2}{|c|}{ Respon keluaran } & \multicolumn{1}{|c|}{ Hasil } \\
\hline 1. & $\begin{array}{l}\text { Apa koneksi } \\
\text { bluetooth Arduino } \\
\text { dengan ponsel } \\
\text { android berhasil? }\end{array}$ & $\begin{array}{l}\text { Bluetooth ponsel } \\
\text { terhubung dengan } \\
\text { mobil robot } \\
\text { vacuum cleaner. }\end{array}$ & $\begin{array}{l}{[\sqrt{ }] \text { Diterima }} \\
{[] \text { Ditolak }}\end{array}$ \\
\hline 2 & $\begin{array}{l}\text { Apa Penggunaan } \\
\text { klik tombol cari } \\
\text { berhasil? }\end{array}$ & $\begin{array}{l}\text { Mencari daftar } \\
\text { bluetooth yang } \\
\text { tersambung } \\
\text { dengan ponsel } \\
\text { android. }\end{array}$ & $\begin{array}{l}{[\sqrt{ }] \text { Diterima }} \\
{[] \text { Ditolak }}\end{array}$ \\
\hline 3 & $\begin{array}{l}\text { Apa Penggunaan } \\
\text { klik Tombol } \\
\text { hubungkan } \\
\text { berhasil? }\end{array}$ & $\begin{array}{l}\text { Menghubungkan } \\
\text { ponsel Android } \\
\text { dengan mobil robot } \\
\text { vacuum cleaner. }\end{array}$ & $\begin{array}{l}{[\sqrt{ }] \text { Diterima }} \\
{[] \text { Ditolak }}\end{array}$ \\
\hline 4 & $\begin{array}{l}\text { Apa Penggunaan } \\
\text { klik Tombol on } \\
\text { berhasil? }\end{array}$ & $\begin{array}{l}\text { Menjalankan } \\
\text { mobil robot } \\
\text { vacuum cleaner }\end{array}$ & $\begin{array}{l}{[\sqrt{ }] \text { Diterima }} \\
{[] \text { Ditolak }}\end{array}$ \\
\hline 5 & $\begin{array}{l}\text { Apa Penggunaan } \\
\text { klik Tombol off } \\
\text { berhasil? }\end{array}$ & $\begin{array}{l}\text { Memberhentikan } \\
\text { mobl robot vacuum } \\
\text { cleaner }\end{array}$ & $\begin{array}{l}{[\sqrt{ }] \text { Diterima }} \\
{[] \text { Ditolak }}\end{array}$ \\
\hline
\end{tabular}

Penjelasan pada tabel 1 skenario pengujian penggunaan aplikasi android mobil robot vacuum cleaner: dari skenario pengujian yang diujikan dari aplikasi android, yakni

1. koneksi Bluetooth dari mobil robot vacuum cleanerdengan ponsel android berhasil berfungsi,

2. penggunaan tombol cari (berfungsi mencari koneksi Bluetooth yang sudahk di hububgkan dari ponsel) berhasil berfungsi,

3. tombol hubungkan (berfungsi menghubungkan koneksi Bluetooth yang sudah terhubung untuk masuk ke menu utama) berhasil berfungsi,

4. tombol on (berfungsi menyalakan kembali mobil robot agar bergerak) berhasil berfungsi dan tombol off (berfungsi untuk memberhentikan gerak mobil robot) berhasl berfungsi. 
Tabel 2. skenario pengujian pergerakan mobil robot vacuum cleaner.

\begin{tabular}{|c|c|c|}
\hline No & $\begin{array}{c}\text { Pengujian mobil robot vacuum } \\
\text { cleaner }\end{array}$ & Hasil \\
\hline 1. & $\begin{array}{l}\text { Apa mobil robot vacuum cleaner } \\
\text { dapat berjalan? }\end{array}$ & $\begin{array}{l}\text { [ ] }] \text { Diterima } \\
\text { [] Ditolak }\end{array}$ \\
\hline 2 & $\begin{array}{l}\text { Apakah sensor gerak ultrasonik } \\
\text { dapat mendeteksi halangan? }\end{array}$ & $\begin{array}{l}\text { [V] Diterima } \\
\text { [] Ditolak }\end{array}$ \\
\hline 3 & $\begin{array}{l}\text { Apakah saat mobil robot vacuum } \\
\text { cleaner mendeteksi halangan, } \\
\text { mobil robot dapat berbelok } \\
\text { mencari jalan yang tidak ada } \\
\text { halangan dengan metode fuzzy } \\
\text { yang diterapkan? }\end{array}$ & $\begin{array}{l}{[\sqrt{ }] \text { Diterima }} \\
{[] \text { Ditolak }}\end{array}$ \\
\hline 4 & $\begin{array}{l}\text { Apakah berat vacuum cleaner } \\
\text { mempengaruhi gerak mobil robot } \\
\text { menjadi lambat? }\end{array}$ & $\begin{array}{l}{[\sqrt{ }] \text { Diterima }} \\
\text { [] Ditolak }\end{array}$ \\
\hline 5 & $\begin{array}{lcr}\text { Apakah jika } & \text { baterai } & \text { untuk } \\
\text { menggerakkan } & \text { mobil } & \text { robot } \\
\text { vacuum } & \text { cleaner } & \text { sudah habis perlu } \\
\text { diganti? }\end{array}$ & $\begin{array}{l}{[\sqrt{ }] \text { Diterima }} \\
\text { [] Ditolak }\end{array}$ \\
\hline 6 & $\begin{array}{l}\text { Apakah jika baterai untuk vacuum } \\
\text { cleaner sudah habis perlu di cas } \\
\text { ulang? }\end{array}$ & $\begin{array}{l}{[\sqrt{ }] \text { Diterima }} \\
\text { [] Ditolak }\end{array}$ \\
\hline
\end{tabular}

Penjelasan pada Tabel 2 skenario pengujian pergerakan mobil robot vacuum cleaner. Skenario ini berfungsi untuk ujicoba dalam gerak mobil robot vacuum cleaner seperti mobil robot dapat bergerak jalan,

1. mobil robot vacuum cleaner dapat berjalan dan berfungsi,

2. sensor gerak ultrasonik dapat mendeteksi halangan dan berfungsi,

3. saat mobil robot vacuum cleaner mendeteksi halangan, mobil robot dapat berbelok mencari jalan yang tidak ada halangan dengan metode fuzzy yang diterapkan,

4. berat vacuum cleaner mempengaruhi gerak mobil robot menjadi lambat,

5. baterai untuk menggerakkan mobil robot vacuum cleaner sudah habis perlu diganti, dan baterai untuk vacuum cleaner sudah habis perlu di cas ulang.

Tabel 3. ujicoba pengujian pemasangan aplikasi dalam ponsel android.

\begin{tabular}{|l|l|l|}
\hline No & $\begin{array}{l}\text { Pengujian pemasangan aplikasi } \\
\text { Android }\end{array}$ & \multicolumn{1}{c|}{ Hasil } \\
\hline \multirow{2}{*}{1.} & $\begin{array}{l}\text { Apakah Pemasangan aplikasi ke } \\
\text { versi 4.3 (jelly bean) berhasil? }\end{array}$ & $\begin{array}{l}{[\sqrt{ }] \text { Diterima }} \\
{[] \text { Ditolak }}\end{array}$ \\
\hline \multirow{2}{*}{2} & $\begin{array}{l}\text { Apakah Pemasangan aplikasi ke } \\
\text { versi 4.4 (kitkat) berhasil? }\end{array}$ & $\begin{array}{l}{[\sqrt{ }] \text { Diterima }} \\
{[] \text { Ditolak }}\end{array}$ \\
\hline \multirow{2}{*}{3} & $\begin{array}{l}\text { Apakah Pemasangan aplikasi ke } \\
\text { versi 5.0 (lollipop) berhasil? }\end{array}$ & $\begin{array}{l}\text { [ }] \text { Diterima } \\
\text { [] Ditolak }\end{array}$ \\
\hline \multirow{2}{*}{4} & $\begin{array}{l}\text { Apakah Pemasangan aplikasi ke } \\
\text { versi 6.0 (marshmallow) berhasil? }\end{array}$ & $\begin{array}{l}\text { [ }] \text { Diterima } \\
\text { [] Ditolak }\end{array}$ \\
\hline
\end{tabular}

Penjelasan pada tabel 3 ujicoba pemasangan aplikasi ponsel Android : dalam skenario pemasangan aplikasi ponsel Android, aplikasi di ujicoba dipasangkan dari berbagai versi O.S Android mulai dari versi 4.3 (jellybean) hingga versi 6.0 (marshmallow) agar memberitahu bahwa aplikasi ini dapat berjalan dan bisa digunakan dari versi tersebut.

\subsection{Survei kelayakan aplikasi kepada pengguna}

Survei kelayakan adalah sebuah survei agar mengetahui seberapa layaknya aplikasi dapat berjalan sesuai pengguna yang menggunakannya. Survei dilakukan dengan cara peneliti membuat 4 pertanyaan yang diujikan ke 5 orang, kelayakan akan dinilai dari terhadap penggunaan mobil robot vacuum cleaner.

Tabel 4. pertanyaan survei uji aplikasi pengguna

\begin{tabular}{|l|c|c|c|c|}
\hline \multirow{2}{*}{ Pernyataan } & \multicolumn{4}{|c|}{ Jawaban } \\
\cline { 2 - 5 } & $\begin{array}{c}\text { Sangat } \\
\text { setuju }\end{array}$ & Setuju & $\begin{array}{c}\text { Tidak } \\
\text { setuju }\end{array}$ & $\begin{array}{c}\text { Sangat } \\
\text { tidak } \\
\text { setuju }\end{array}$ \\
\hline $\begin{array}{l}\text { Tampilan aplikasi } \\
\text { dapat dilihat } \\
\text { dengan jelas }\end{array}$ & 3 & 2 & & \\
\hline $\begin{array}{l}\text { Tampilan } \\
\text { background } \\
\text { mengganggu } \\
\text { menu utama }\end{array}$ & 1 & 4 & & \\
\hline $\begin{array}{l}\text { Aplikasi dapat } \\
\text { berfungsi sesuai } \\
\text { dengan fungsinya }\end{array}$ & 1 & 4 & & \\
\hline $\begin{array}{l}\text { Tombol dalam } \\
\text { aplikasi bisa } \\
\text { berfungsi dengan } \\
\text { baik }\end{array}$ & 1 & 4 & & \\
\hline
\end{tabular}

Kesimpulan : dari jumlah jawaban yang didapatkan, mayoritas pengguna menjawab setuju, oleh karena itu aplikasi mobil robot vacuum cleaner dapat dinyatakan dengan layak.

\section{KESIMPULAN DAN SARAN}

\subsection{Kesimpulan}

Kesimpulan dari penelitian ini adalah sebagai berikut.

1. Dari prosedur penelitian yang dilaksanakan aplikasi dapat dijalankan dengan baik dan sistem yang digunakan untuk pergerakan mobil berhasil dikembangkan.

2. Berdasarkan hasil pengujian yang dilakukan software dan hardware dari penelitian yang dilakukan dapat berhasil dikembangkan dengan baik.

3. Berdasarkan hasil pengujian yang dilaksanakan diketahui bahwa data hasil uji jarak dari sensor ultrasonik mobil robot vacuum cleaner menunjukkan disaat dalam beberapa kondisi jarak tertentu apakah mobil robot akan berhenti dan belok ataupun gerak lurus saja, seperti kondisi pertama disaat mobil robot dalam jarak $30 \mathrm{~cm}$ dari penghalang maka gerak mobil robot akan berhenti, belok kri/kanan dan maju gerak lurus, dst.

4. Berdasarkan hasil pengujian diketahui bahwa saat mendeteksi halangan, mobil robot vacuum cleaner akan berhenti sementara dan berbelok kanan/kiri untuk mencari jalan yang bebas halangan dan akan bergerak lurus/maju kembali. 


\subsection{Saran}

Saran adalah masukkan untuk peneliti agar penelitian yang dikerjakan dapat dikembangkan lagi dan disempurnakan lagi oleh peneliti lain, saran yang bisa ditulis yaitu :

1. Pemberitahuan jika baterai untuk mobil robot vacuum cleaner perlu ditambahkan bagi peneliti selanjutnya agar pengguna dapat mengetahui bahwa baterai yang digunakan untuk menggerakkan mobil robot vacuum cleaner itu habis dengan cara seperti menambahkan buzzer (pertanda suara) jika baterai mau habis.

2. Peneliti selanjutnya dapat menambahkan pemeberitahuan dalam aplikasi saat jangkauan jarak ponsel Android dengan mobil robot vacuum cleaner terputus karena terbatasnya jangkauan bluetooth, seperti notifikasi tulisan di aplikasi "jangkauan mobil robot melebihi ponsel".

3. Peneltian selanjutnya diharapkan dapat menambahkan navigasi mobil robot vacuum cleaner, jika area yang sudah dibersihkan maka mobil robot tidak melewati area yang telah bersih lagi.

\section{DAFTAR PUSTAKA}

[1] H., G. (2018). PERANCANGAN ROBOT VACUUM CLEANER. Jurnal Bangkit Indonesia.

[2] Ihsan, M. A., Irawan, J. D., \& Auliasari, K. (2020). Sistem Penetu Karyawan Terbaik Dengan Metode Fuzzy Mamdani Menggunakan Radio Frequency Identification (RFID)Sebagai Presensi. JATI, 1-8.

[3] Ikame. (2017). ikame vacuum cleaner. Retrieved from jenis dan fungsi vacuum cleaner: https://ikame.co.id/jenis-dan-fungsi-vacuumcleaner/
[4] Lismardiana. (2018). Fuzzy Multi-Atribute Decision Making (Fuzzy MADM) Dengan Metode Saw Dalam Penentuan Lulusan Mahasiswa Berprestasi. 37 - 46.

[5] Nanda, H. (2016). Remote Control Sistem Mini Blimp via Android Smartphone with Communication Using Bluetooth Based On Mikrokontroller. Universitas Sanata Dharma.

[6] S, B. W. (2016). Penerapan Fuzzy MADM Model Yager Pada Sistem Pendukung Keputusan Seleksi Penerimaan Siswa Baru Smp N 4 Paku. Jurnal Ilmiah DASI, 69-75.

[7] Salamadian. (2019). pengertian android. Retrieved from salamadian.com: https://salamadian.com/pengertian android/

[8] Setiawan, D. (2016). Rancang Bangun Robot Mobil kontrol Sederhana menggunakan Arduino Berbasis Android Sistem. Jurnal Sains teknologi dan industri, 101-107.

[9] Sumarsono. (2018). Pengembangan Mikrokontroler Sebagai Remote Control Berbasis Android. Jurnal Teknik Informatika.

[10] Suwanda, I. (2014). Rancang Bangun Omni Wheel Penyedot Debu Menggunakan Sensor Accelerometer Basis Mikrokontroler ATMega16.

[11] Yoga, F. (2016, Maret 16). mengenal arduino software ide. Retrieved from sinau arduino: https://www.sinauarduino.com/artikel/mengenal -arduino-software-ide/

[12] Ihsan, M. A., Irawan, J. D., \& Auliasari, K. (2020). Sistem Penetu Karyawan Terbaik Dengan Metode Fuzzy Mamdani Menggunakan Radio Frequency Identification (RFID)Sebagai Presensi. JATI, 1-8. 